See discussions, stats, and author profiles for this publication at: https://www.researchgate.net/publication/275587570

\title{
Is the Production of Embryos in Small-Scale Farming an Economically Feasible Enterprise?
}

Article in Reproduction in Domestic Animals · April 2015

Dol: 10.1111/rda.12526 · Source: PubMed

CITATIONS

5 authors, including:

Zazil Sánchez

Universidad Nacional Autónoma de México

1 PUBLICATION 2 CITATIONS

SEE PROFILE

Marco Alarcón

Universidad Veracruzana

11 PUBLICATIONS 16 CITATIONS

SEE PROFILE

Some of the authors of this publication are also working on these related projects:

Project Medicina poblacional veterinaria View project

Animal reproduction View project
Miguel A Lammoglia

Universidad Veracruzana

45 PUBLICATIONS 836 CITATIONS

SEE PROFILE

Juan JOSE Romero

Universidad Nacional (National University) de Costa Rica 172 PUBLICATIONS 791 CITATIONS

SEE PROFILE 


\title{
Is the Production of Embryos in Small-Scale Farming an Economically Feasible Enterprise?
}

\author{
Z Sánchez ${ }^{1}$, MA Lammoglia ${ }^{2}$, MA Alarcón ${ }^{2}, J^{\prime}$ Romero $^{3}$ and CS Galina ${ }^{1}$ \\ ${ }^{1}$ Departamento de Reproducción, Facultad de Medicina Veterinaria y Zootecnia, Universidad Nacional Autónoma de México, Mexico City, Mexico; \\ ${ }^{2}$ Facultad de Ciencias Biológicas y Agropecuarias, Universidad Veracruzana, Tuxpan, México; ${ }^{3}$ Escuela de Medicina Veterinaria, Universidad \\ Nacional, Heredia, Costa Rica
}

\begin{abstract}
Content
The present assay attempts to evaluate the feasibility of using embryo transfer in small community farmers by in vivo study and by modelling the results obtained. From the total of 59 donor cows, $62.7 \%$ responded to treatment, with a significant difference $(\mathrm{p}=0.002)$ in the percentage of the response between breeds, being $90.5 \%(19 / 21)$ in Holstein and $47.4 \%(18 / 38)$ in Brahman. A total of 283 embryos were graded as transferable, while 141 as non-transferable, without difference in the percentage of transferable embryo by breed $(\mathrm{p}=0.18)$. The mean of transferable embryos graded as class I and II was not different between Holstein and Brahman $(\mathrm{p}=0.96$ and $\mathrm{p}=0.92$, respectively); besides, no differences were observed in the other grades (non-transferable). The highest difference in costs, regardless of its quality by breed, was seen in the lower levels of probable fertility of the embryo transferred, even reaching several hundred dollars. When modelling the expected costs for embryo produced and transferred, values can reach nearly $\$ 2000.00$ when the probable fertility is only $10 \%$. However, when the probable fertility was $60 \%$, embryo cost was close to $\$ 300.00$. This technology seems to be viable on average or high-scale systems, having a superovulatory response between 60 and $80 \%$ with 4-6 transferrable embryos. Yet, in small-scale farming, due to the reduced number of donors and/or recipients, the costs surpass the economical feasibility of the technique.
\end{abstract}

\section{Introduction}

The industry of embryo transfer (ET) has grown considerably in the last 20 years. In a survey carried out by Perry (2013), it was shown that the use of ET has emerged as an important tool for the improvement of cattle. However, in a review, Hasler (2003) stated that nearly all of the 500000 embryos produced worldwide from superovulated cows are from animals raised in temperate zones and not in the tropics. Nonetheless, several reports have been published to favour the use of this technique particularly from Brazil and Argentina where the cattle industry is an important source of revenues and has grown considerably in the last few years (Baruselli et al. 2006; Baruselli et al. 2010; Nasser et al. 2004). Recent reviews with a considerable number of animals being exposed to the ET procedure (Baruselli et al. 2010; Nasser et al. 2004) claimed that the technique is probably affordable only within large producers as with them, the popularity of ET in the region seems to be on the raise.

The opposite appears to be the case in others with scarce infrastructure for development. In effect in a recent study undertaken in Mexico, it was calculated that the final cost of a replacement F1 heifer (Bos taurus $\mathrm{x}$ Bos indicus) using embryo transfer soared to almost 3000 dollars (Alarcón et al. 2010). This observation is in agreement with Hasler's review (2003) where he indicates that the current success level of superovulation represents a significant obstacle, even in industrialized countries to the future growth of the ET industry. According to the author as long as mean embryo production remains at less than six, with a range of ( 0 to $>60$ ), with $20 \%$ of donors producing zero embryos, this technology will remain an expensive, inefficient procedure.

Several researchers have provided sufficient evidence to sustain that the best cross-breeding programme to produce milk in the tropics is the direct cross between Bos taurus and Bos indicus (F1). The problem arises when the farmer faces the challenge to breed this crossbred animal. If the choice is to cross with Bos taurus, the resulting product is quite vulnerable to the harsh environmental condition in the tropics. If, on the other hand, the selection is to sire with Bos indicus, then the offspring will be deficient in milk production (Madalena 1993). Another alternative is to transfer F1 embryos to F1 dams, hence avoiding the hazards of cross-breeding (Cunningham 1989).

The purpose of this study is to calculate the costs related to the production of F1 embryos and by modelling assess the value of this technique in cattle raised in undersized scale farming to discern the feasibility of the procedure as an alternative tool for small farmers to improve their genetic stock maintaining the hybrid vigour of the cross-bred Bos taurus x Bos indicus.

\section{Material and Methods Location}

Bos indicus embryos were obtained from two commercial farms located in the State of Veracruz, Mexico, at $17^{\circ} 03^{\prime}$ de latitude north and $93^{\circ} 36^{\prime}$ and $98^{\circ} 38^{\prime}$ longitude west (INEGI, 2012 ${ }^{1}$ ). Annual mean precipitation averages $1500 \mathrm{~mm}^{3}$, temperature ranges between 11 and $32^{\circ} \mathrm{C}$, and altitude below 300 metres above sea level.

${ }^{1}$ http://www.inegi.org.mx/prod_serv/contenidos/espanol/bvinegi/productos integracion/estd_perspect/ver/Pers-ver.pdf 
Embryos from Bos taurus were obtained in the State of Querétaro situated at $20^{\circ} 35^{\prime}$ and $20^{\circ} 37^{\prime}$ longitude north and at $100^{\circ} 19^{\prime}$ and $100^{\circ} 21^{\prime}$ longitude west. Ambient temperature ranges between 18 and $24^{\circ} \mathrm{C}$ with an average rainfall between 400 and $500 \mathrm{~mm}^{3}$ (INEGI, $2012^{2}$ ). The three farms had a total population averaging 200 cows. Embryos were obtained during the summer of 2013 by two of the authors (Alarcón and Lammoglia) which have considerable experience in the technique. After flushing and grading, suitable embryos were frozen according to standard procedures.

\section{Animals}

A total of 59 cows were used, 38 Brahman and 21 Holstein. Animals selected were at least 90 days postpartum and had a mean of five calvings without gross pathological conditions. The animals were cycling at the onset of the superovulatory treatment and had a body condition score of 3-4 on a scale of 1-5 (Pullan 1978).

\section{Preparation for embryo retrieval}

Donor animals received two doses of $100 \mu \mathrm{g}$ of GnRH intramuscularly (Zoetis, México) within a 7-day interval. After the second GnRH application, an injection of $25 \mathrm{mg}$ of dinoprost (PgF2 $\alpha$, Lutalyse, Zoetis México) followed. Twenty four hours later, oestrous detection began continuously for $72 \mathrm{~h}$. Cows were declared in oestrus if they received three or more mounts. Ten days after the onset of oestrus, a rectal examination was performed to verify the presence of a corpus luteum (CL). One day after CL identification, cows received FSH treatment, and the total dose of FSH-P for $B$. indicus cows was 280 and $400 \mathrm{mg}$ for $B$. taurus. The reason for this disparity is that $B$. indicus cows are more susceptible to the gonadotrophin treatment as there is a pronounced effect on the follicular milieu and more immature follicles are recruited following treatment (Baruselli et al. 2006). The total dose was divided into eight applications with decreasing dosages $12 \mathrm{~h}$ apart starting at $50,40,30$ and $20 \mathrm{mg}$. In the third day of the FSH treatment, an injection of $25 \mathrm{mg}$ of prostaglandin $\mathrm{PgF} 2 \alpha$ was administered. Animals were AI 12 and $24 \mathrm{~h}$ after the onset of oestrus. Cows forming more than 2 CL's were chosen suitable for embryo collection 7 days after the onset of oestrus.

\section{Embryo grading}

Embryos were immediately evaluated by a qualified technician and classified as grade 1 (I) excellent and good, grade 2 (II) fair, grade 3 (III) poor and grade 4 (IV) dead or degenerating according to the criteria described by Bó and Mapletoft (2013).

\footnotetext{
${ }^{2}$ http://www.inegi.org.mx/prod_serv/contenidos/espanol/bvinegi/productos/ integracion/estd_perspect/qro/pers-qro.pdf
}

\section{Statistical analysis}

\section{Descriptive statistics}

The global percentage of responders as well as the specific percentage by breed were calculated and compared using a chi-square test. Means of embryos obtained from responders, by grade and by breed, were compared using Student's $t$-test. In both chi-square and Student's $t$-test, the $\alpha$ value was set in 0.05 .

\section{Economical assessment}

In order to determine the cost of embryos produced from those selected to be transferable, the percentage of cows responding to superovulation, plus the average of embryos, was considered viable to be transferred (categories I and II). Embryos classified as poor or degenerate were not considered in the calculations. Also, the model included the possible rate of success $(0-100 \%)$. Using this approach, values were adjusted taking into account the percentage of cows not responding.

On the other hand, the preparation of a donor cow, including hormonal therapy, material to collect embryos, semen, veterinary services, labour and feeding costs, was 512.75 (US dollars). Also, the cost to prepare recipient animals was estimated in 106.21 (US dollars) which include hormonal therapy, material for transferring embryos of superovulated cows to each recipient, feeding, labour and veterinary services.

Though a deterministic model, a simulating accounting for breed of the animal (Holstein and Brahman) was compared with three different sources of variation (a) the response to superovulation, (b) the number of embryos produced and (c) the probable fertility of embryos according to their quality (grade I $75 \%$, grade II $50 \%$ ). This analysis was carried out in three phases (i) modelling the possible costs based in the superovulatory response and the average of transferrable embryos obtained in the survey with ranges from $(0-100 \%)$ indistinctively of the embryo grading, (ii) modelling the cost assuming superovulatory responses from 50 to $80 \%$ and three averages of transferable embryos (5-10 and $15)$ for all the fertility ranges $(0-100 \%)$. All these calculations without taking in consideration embryo grading, (iii) a standardized cost of transferable embryos produced per breed was calculated in three conditions: (a) according to the superovulatory rates and the average of transferable embryos reported by Ake-López et al. (1995), (b) based on the observed results for these parameters in the present study and (c) an expected (modelled) estimation for any breed, with a $80 \%$ of superovulatory rate and two fixed means ( 8 and 12) of transferable embryos per cow.

\section{Results \\ Descriptive statistics}

From the total of 59 donor cows, $62.7 \%$ responded to treatment, with a significant difference $(p=0.002)$ in the 
percentage of the response between breeds, being $90.5 \%$ $(19 / 21)$ in Holstein and 47.4\% (18/38) in Brahman. A total of 283 embryos were graded as transferable, while 141 as not transferable, without difference in the percentage of transferable embryo by breed $(\mathrm{p}=$ 0.181 ). The means, according to embryo grading, were also not different in all grades. The amount of embryos produced graded by quality, and its mean and standard deviation are described in Table 1.

\section{Costs estimates}

The estimated cost for the production and transferring of embryos regardless of their quality and based on the superovulatory response was $73 \%$ more expensive in Brahman than Holstein if the fertility estimated was only $10 \%$; the cost is reduced to approximately $35 \%$ if the fertility augments to $80 \%$ (Fig. 1). This result, with the specific variations in the proportional differences, is similar for the two types of transferable embryos (grades I and II).

On the other hand, the most expensive embryos were those graded as II from Brahman cows, highly influenced by the low superovulatory response that leads to a low absolute production (Table 1). They were followed by those of Holstein graded as II; subsequently, with very similar results in embryos graded as I for Holstein and Brahman cows, especially when the percentage of embryo fertility is over $50 \%$.

The highest difference in costs, regardless of its quality by breed, were seen in the lower levels of probable fertility of the embryos transferred, even reaching several hundred dollars; thus, for example, the Brahman embryos graded II cost \$2811.9 more than the Holstein at $10 \%$ fertility, of the same grade. This difference falls steadily through various probable fertility rates; however, even in the best of scenarios ( $100 \%$ fertility), the variance was \$281.2 (Fig. 1).

When modelling the expected costs for embryo produced and transferred, with rates of fertility to the possible range of superovulatory response $(0-100 \%)$, extreme values were obtained when the response rates are low and the number of transferable embryos is also small, with the consequent reverse condition when both elements are high. These differences can, for example, reach nearly $\$ 2000.00$ when the probable fertility is only $10 \%$; however, the absolute and relative differences decrease as the probable fertility increase, reaching reduced absolute differences at the end of range (Fig. 2).

Figure 2 depicts six possible modelling scenarios, while only comparing $50 \%$ responders +15 embryos or $80 \%$ responders with 10 embryos (values usually reported in the literature), similar results were observed when this comparision was carried out. However, if an scenario $50 \%$ responders but only averaging 10 embryos or $80 \%$ responders with five embryos, the costs rise considerably as even having a reasonable response from the donors (more than $50 \%$ ) if the fertility averages the same, the costs augment between 90 and 150 US dollars.

When comparing the standardized cost per embryo produced in three different scenarios (i) using the data reported by Ake-López et al. (1995) as an average response reported in the literature, (ii) the data actually obtained in the field study and (iii) results obtained by modelling, costs are standardized using the figures in the data obtained in the field study. Holstein embryos obtained in Ake's study are more expensive to produce according to their data. On the contrary, in our field study, the Brahman embryos were the most expensive. Moreover, when the number of transferrable embryos changes from the hypothetical response of 8 or 12 embryos, there is a substantial reduction of $20-27 \%$ in the costs (Table 2).

\section{Discussion}

The average response of embryos recovered is in agreement with current figures gathered recently by the International Embryo Transfer Society (IETS) (Perry 2013). However, as in many studies, there is a bias when comparing two breeds and moreover when using the average as a response variable. In effect, the

Table 1. Descriptive statistics of embryos collected from Holstein and Brahman cows, graded by quality and transferable/not transferable condition

\begin{tabular}{|c|c|c|c|c|c|c|c|c|c|}
\hline \multirow[b]{2}{*}{ Embryo grading } & \multicolumn{3}{|c|}{ Holstein } & & \multicolumn{3}{|c|}{ Brahman } & & \multirow[b]{2}{*}{ p Value* } \\
\hline & $\mathrm{n}$ & Mean & SD & & $\mathrm{n}$ & Mean & $\mathrm{SD}$ & & \\
\hline I & 102 & 6.00 & 3.37 & & 109 & 6.06 & 3.61 & & 0.963 \\
\hline II & 36 & 1.89 & 3.48 & & 36 & 2.00 & 2.66 & & 0.919 \\
\hline III & 30 & 1.76 & 1.52 & & 53 & 2.94 & 3.86 & & 0.242 \\
\hline IV & 29 & 1.53 & 2.01 & & 29 & 1.61 & 2.12 & & 0.901 \\
\hline Transferable (I,II) & 138 & 7.26 & 6.44 & & 145 & 8.06 & 4.40 & & 0.667 \\
\hline Not transferable (III, IV) & 59 & 3.11 & 2.05 & & 82 & 4.56 & 3.42 & & 0.131 \\
\hline Superovulatory response (\%) & & & & 90.5 & & & & 47.4 & 0.002 \\
\hline Transferability rate $(\%)$ & & & & 70.1 & & & & 63.4 & 0.181 \\
\hline
\end{tabular}

SR, percentage of cows with superovulatory response.

* p value for differences of means according to the embryo quality between breeds. 
Fig. 1. Estimated costs of embryos according to grading in different possible fertility rates, obtained from the superovulatory response $(90.5 \%$ for Holstein and $47.4 \%$ for Brahman)
Fig. 2. Expected costs of transferable embryos at different percentages of fertility, fixing the rate of cows with superovulatory response in two levels $(80 \%$ and $50 \%)$ and three different means of embryos obtained per cow $(15,10$ and 5)
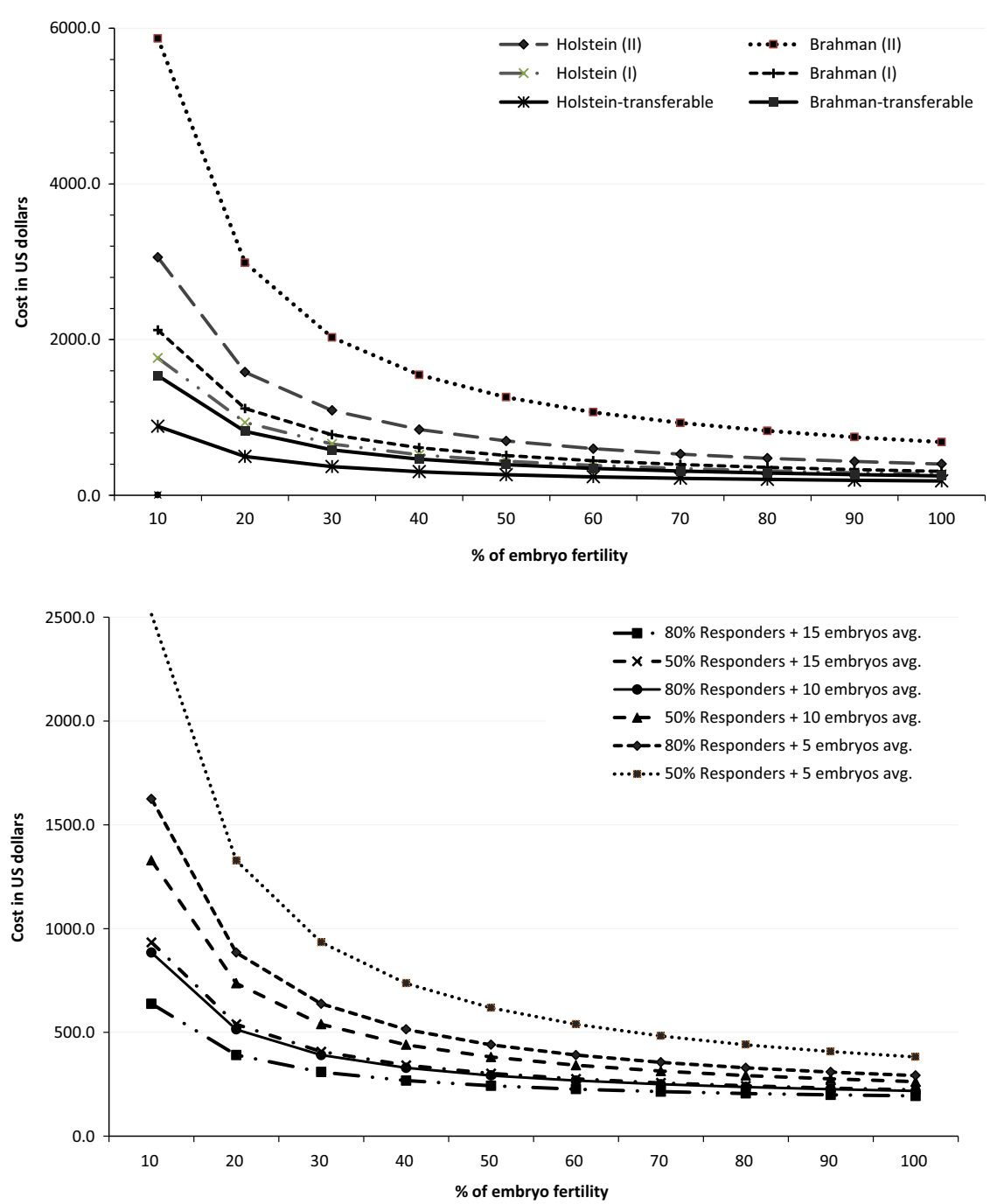

average in our study was 7.65 comparing favourably to Perry's worldwide data 6.67 embryos per flush. First of all, studies depend largely in what is measured as transferrable embryo and consideration such as distance and season (Bastidas and Randel 1986; Bényei et al. 2006) management on a farm (Stroud and Hasler 2006) and embryo grading (Aguilar et al. 2002) play an important role in establishing the average response. Perry's survey (2013) also illustrates the difficulty in gathering sufficient and accurate information about the accountability of the technique as only countries with an established embryos transfer programme, that is large countries provide the information. For example, the majority of African and Asian countries have not responded to the IETS surveys. Coincidently, these are the regions where small community farmers predominate and where international organizations have vested considerable resources to make this technique available and affordable. For example, in a study in rural México sponsored by FAO (Montiel et al. 2006), it became apparent the variability in the response between farmers. One later study in the same region, calculated that the cost for producing a replacement heifer soared to almost 3000 US dollars (Alarcón et al. 2010). Considering the added value in milk production when the cost of this replacement of an undefined breed is 900 dollars, it is uneconomical at the moment to choose changing the replacement programme in a small farm using embryo transfer. The difference in price does not compensate for the revenues obtained in disparity on milk production between the two systems.

In spite of the embryos produced and catalogued as transferable, $33.3 \%$ of the total number of cells recovered were not suitable for embryo transfer. This result is in accord with Hasler (2003) and many others (for review, see Bó and Mapletoft 2014) and remains as an important added cost in embryo production. The differences observed between breeds in relation to embryos production and quality are widely acknowledged (for review, see Barros and Nogueira 2001), and again many factors such as housing, nutrition and management play an important role in this disparity (Bényei et al. 2006; Betteridge 2003). In effect, Hasler (2014) in a review underlines the economical importance 
Table 2. Costs (in US dollars) of transferred embryos for Brahman and Holstein cows in three different scenarios (reference, observed and modelled) at different rates of superovulatory response, average of transferable embryos and embryo fertility

\begin{tabular}{|c|c|c|c|c|c|c|c|c|c|c|c|c|}
\hline \multirow[b]{2}{*}{$\begin{array}{l}\text { Calculation } \\
\text { base }\end{array}$} & \multicolumn{4}{|c|}{ Brahman } & \multicolumn{4}{|c|}{ Holstein } & \multicolumn{4}{|c|}{ Modelled $^{\mathrm{c}}$} \\
\hline & $\%$ SOv. Resp. & Transf. Embryo & Cost & $\begin{array}{l}\text { Emb. } \\
\text { Fert. }\end{array}$ & $\begin{array}{l}\text { \% SOv. } \\
\text { Resp. }\end{array}$ & $\begin{array}{l}\text { Transf. } \\
\text { Embryo }\end{array}$ & Cost & $\begin{array}{l}\text { Emb. } \\
\text { Fert. }\end{array}$ & $\begin{array}{l}\text { \% SOv. } \\
\text { Resp. }\end{array}$ & $\begin{array}{l}\text { Transf. } \\
\text { Embryo }\end{array}$ & Cost & $\begin{array}{l}\text { Emb. } \\
\text { Fert. }\end{array}$ \\
\hline \multirow[t]{3}{*}{ Reference $^{\mathrm{a}}$} & 75.0 & 7.8 & 244.46 & 63.4 & 86.4 & 6.6 & 269.59 & 70.0 & 80.0 & 12.0 & 182.51 & 70 \\
\hline & & & 301.86 & 44.8 & & & 337.43 & 50.0 & & & 213.03 & 50 \\
\hline & & & 303.62 & 44.8 & & & 339.51 & 40.0 & & & 239.74 & 40 \\
\hline \multirow[t]{3}{*}{ Observed $^{\mathrm{b}}$} & 47.4 & 8.1 & 318.16 & 63.4 & 90.5 & 7.3 & 229.30 & 70.0 & 80.0 & 8.0 & 220.66 & 70 \\
\hline & & & 406.16 & 44.8 & & & 280.41 & 50.0 & & & 266.44 & 50 \\
\hline & & & 408.87 & 44.8 & & & 281.98 & 40.0 & & & 306.50 & 40 \\
\hline
\end{tabular}

\% SOv. Resp., percentage of cows with superovulatory response; Transf. Embryo, Transferable embryo; Emb. Fert., Embryo fertility.

${ }^{\text {a }}$ Reference $=$ from Ake-López et al. (1995).

${ }^{\mathrm{b}}$ Observed $=$ from this study.

${ }^{\mathrm{c}}$ It represents any breed in an expected superovulatory response of $80 \%$ with 12 and 8 transferable embryos on average.

of other factors related to ET; for example, in 1978, the cost per dose of the original Armour FSH-P was $\$ 6.50$ and the ET practitioner charge for his services $\$ 500$. Today, the cost of the available FSH preparations exceeds $\$ 100$ per dose and the ET practitioner fees are half or less than what they were 35 years ago. What impact will this have on the economics of embryo transfer?

The purpose of this communication is centered in establishing points of equilibrium where the technique could be feasible under the conditions of small community farmers. This goal can be achieved simply by calculating the cost of producing an embryo vs purchasing it commercially, or with the complexity related to the long-term investment of improving a particular breed during a lifetime production compared to the existing livestock in the area. Concerning the former, bearing in mind a commercial cost of $\$ 250$ to $\$ 350$ USD per gestation, these figures compared favourably to the ones of the present study, \$318 to \$408 USD for Brahman and \$230 to \$340 USD for the Holsteins. Bolivar and Maldonado working in Colombia (2008) reported costs close to $\$ 360$ USD. Nonetheless, this investment per embryo transferred terminating in a pregnancy does not take in consideration the added advantage of the local adaptation of the donor cow to the existing conditions in the area. This effect could only be measured in the production of their offspring which is a calculation still lacking in the embryo transfer industry in general.

Many studies particularly in Holstein cows exposed to heat stress (Ambrose et al. 1999; Al-Katanani et al. 2002; Stewart et al. 2011) indicate a higher fertility obtained using ET embryos instead of conventional AI, perhaps these publications are a good example that by not measuring the cost of comparing these two biotechnologies, one could assume that 'ET is better than AI' to solve an old problem of low summer fertility in dairy cattle. In effect in a study on small-scale farming in the south of Brazil, Brockington and Martínez (1996) found that even by improving the number of viable embryos from four with a $50 \%$ fertility rate to six and a corresponding $70 \%$ of pregnancies, the producer faces a waiting period of some 15-20 years for a significant genetic returns from the use of ET.

This lack of response in $37.3 \%$ of the donor animals added to the cost of embryos not considered of optimum quality which can be as high as $40 \%$ (AkeLópez et al. 1995) rise the cost of the technique considerably. Moreover, if the donor animal does not produce any embryos, there is an additional loss of days where the animal is open which ranges in dairy cows from \$3.2 USD to \$5.4 USD (De Vries 2004).

Again there is a wealth of information in the convenience of producing cross-bred embryos (Cunningham 1989), and the resultant heterosis (Madalena 1993) has afforded sufficient information to make this technique attractive to low-scale farming for improving their incomes. However, it does not seem feasible to produce embryos in these enterprises as the failures elevated the costs significantly; for example, it will be necessary to obtain at least an $80 \%$ response in the donor cows with a mean of 4-6 transferrable embryos, three embryo flushings per year and a fertility of $50 \%$ to make this technique economically feasible (Brockington and Martínez 1996). This event is more evident as there are fewer animals in the farm, thus one could place in jeopardy the whole enterprise. At the moment, it seems to be that options to organize an ET programme in small community farmers can be reduced to two possible scenarios (a) purchase embryos from commercial companies (b) produce embryos from large beef or dairy cattle enterprises to obtain the F1 cross-bred animal that could improve milk production under the conditions of small farmers. Both techniques have the disadvantage of a possible poor adaptation of the offspring to the harsh environmental conditions in the tropics. To conclude, embryo production using donor animals from a small enterprise does not seem economically feasible under the present results. However, a good management and selection of the donors might greatly improve the current situation.

The modelling analysis indicate that it will be necessary to augment by almost twofold the response of 
donor animals and the quality of embryos graded as good or excellent to make this technique an attractive proposition to small community farmers in the tropics.

\section{Acknowledgements}

The authors are grateful to the bureau of academic affairs of UNAM (PAPIIT IN211013) for financial assistance.

\section{Conflict of interest}

The authors whose names are listed immediately below certify that they have NO affiliations with or involvement in any organization or entity with any financial interest (such as honoraria; educational grants; participation in speakers' bureaus; membership, employment, consultancies, stock ownership, or other equity interest; and expert testimony or patent-licensing arrangements), or non-financial interest (such as personal or professional relationships, affiliations, knowledge or beliefs) in the subject matter or materials discussed in this manuscript.

\section{Author contributions}

Zazil Sanchez and I were in charge of executing and analysing the data, Marco Alarcón and Miguel A. Lammoglia were involved in the field work, and Juan José Romero participated in the modelling.

\section{References}

Aguilar MM, Galina CS, Merchant $\mathrm{H}$, Montiel F, Canseco R, Márquez YC, 2002: Comparison of stereoscopy, light microscopy and ultrastructural methods for evaluation of bovine embryos. Reprod Domest Anim 37, 341-346.

Ake-López JR, Alfaro ME, Lubos H, 1995: Respuesta superovulatoria en ganado Bos indicus y Bos taurus bajo condiciones tropicales, y el efecto del desarrollo y calidad del embrión sobre el porcentaje de gestación. Veterinaria México 26, 189-193.

Alarcón MA, Galina CS, Corro MD, Asprón MA, 2010: Embryo transfer, a useful technique to be applied small community farms? Trop Anim Health Prod 42, 1135-1141

Al-Katanani YM, Drost M, Monson RL, Rutledge JJ, Krininger CE, Block J, Thatcher WW, Hansen PJ, 2002: Pregnancy rates following timed embryo transfer with fresh or vitrified in vitro produced embryos in lactating dairy cows under heat stress conditions. Theriogenology $\mathbf{5 8}$, 171-182.

Ambrose JD, Drost M, Monson RL, Rutledge JJ, Leibfried Rutledge ML, Thatcher MJ, Kassa T, Binelli M, Hansen PJ, Chenoweth PJ, Thatcher EW, 1999: Efficacy of timed embryo transfer with fresh and frozen in vitro produced embryos to increase pregnancy rates in heat-stressed cattle. J Dairy Sci 82, 2369-2376.

Barros CM, Nogueira MFG, 2001: Embryo transfer in Bos indicus cattle. Theriogenology 56, 1483-1496.

Baruselli PS, de Sá Filho MF, Martins CM, Nasser LF, Nogueira MF, Barros CM, Bó GA, 2006: Superovulation and embryo transfer in Bos indicus cattle. Theriogenology 65, 77-88.

Baruselli PS, Ferreira RM, Sá Filho MF, Nasser LF, Rodrigues CA, Bó GA, 2010: Bovine embryo transfer recipient synchronization and management in tropical environments Reproduction. Fertil Dev 22, 67-74.

Bastidas P, Randel RD, 1986: Seasonal effects on embryo transfer results in Brahman cows. Theriogenology 28, 531540.

Bényei B, Komlosi I, Pecsi A, Pollott G, Marcos $\mathrm{CH}$, de Oliveira Campos A, Lemes MP, 2006: The effect of internal and external factors on bovine embryo transfer results in a tropical environment. Anim Reprod Sci 93, 268-279.

Betteridge KJ, 2003: A history of farm animal embryo transfer and some associated techniques. Anim Reprod Sci 79, 203-244.

Bó GA, Mapletoft RJ, 2013: Evaluation and classification of bovine embryos. Anim Reprod 10, 344-348.

Bó GA, Mapletoft RJ, 2014: Historical perspectives and recent research on superovulation en cattle. Theriogenology 81, 38-48.

Bolivar PA, Maldonado JG, 2008: Análisis de costos de esquemas de transferencia de embriones bovinos utilizados en Colombia. Revista Colombiana de Ciencias Pecuarias 21, 351-364.

Brockington NR, Martínez ML, 1996: The application of embryo transfer in herd improvement for small-scale milk production systems in South-East Brazil. Agric Syst 51, 41-84.

Cunningham EP, 1989: The genetic component of cattle in developing countries. Theriogenology 31, 17-24.

De Vries A, 2004: Economics of delayed replacement when cow performance is seasonal. J Dairy Sci 87, 2947-2958.

Hasler JF, 2003: The current status and future of commercial embryo transfer in cattle. Anim Reprod Sci 79, 245-264.

Hasler JF, 2014: Forty years of embryo transfer in cattle: a review focusing on the journal Theriogenology, the growth of the industry in North America, and personal reminisces. Therigenology 81, 152-169.

Madalena FE, 1993: A simple scheme to utilize heterosis in tropical dairy cattle. World Anim Rev 1, 17-25.

Montiel F, Galina CS, Rubio I, Corro M, 2006: Factors affecting pregnancy rate of embryo transfer in Bos indicus and Bos taurus/Bos indicus cows. J Appl Anim Res 29, 149-152.

Nasser LF, Reis EL, Oliveira MA, Bó GA, Baruselli PS, 2004: Comparison of four synchronization protocols for fixed-time bovine embryo transfer in Bos indicus $\times$ Bos taurus recipients. Theriogenology 62 , 1577-1584.

Perry G, 2013: Statics of embryo collection and transfer in domestic farm animals. Int Embryo Transfer Society Newslett 31, 24-46.

Pullan NB, 1978: Condition scoring of white Fulani cattle. Trop Anim Health Prod 10 110-120.

Stewart BM, Block J, Morelli P, Navarette AE, Amstalden M, Bonilla L, Hansen PJ, Bilby TR, 2011: Efficacy of embryo transfer in lactating dairy cows during summer using fresh or vitrified embryos produced in vitro with sex-sorted semen. J Dairy Sci 94, 3437-3445.

Stroud B, Hasler JF, 2006: Dissecting why superovulation and embryo transfer usually work on some farms but not on others. Theriogenology $\mathbf{6 5}, 65-76$.

Submitted: 2 Oct 2014; Accepted: 29 Mar 2015

Author's address (for Correspondence): CS Galina, Departamento de Reproducción, Facultad de Medicina Veterinaria y Zootecnia, Universidad Nacional Autónoma de México, Mexico City, Mexico.

E-mail: cgalina@unam.mx 